\title{
ATIVIDADE ANTIBACTERIANA DO ÓLEO ESSENCIAL DE Lippia gracilis SCHAUER SOBRE PATÓGENOS DE IMPORTÂNCIA NA INDÚSTRIA DEALIMENTOS
}

\author{
Leandro Icaro Santos Dantas \\ Núcleo de Pesquisa em Plantas Medicinais e Condimentares, Instituto Federal de Educação, \\ Ciência e Tecnologia do Rio Grande do Norte-IFRN, Campus Currais \\ Novos, Aluno do Curso Técnico Integrado em Alimentos, com Ampla Experiência Prática na \\ Área de Microbiologia e Biotecnologia de Alimentos e Bolsista de Iniciação Científica. \\ Email. leandroicarosantos@ hotmail.com

\section{Francisco Ângelo Gurgel da Rocha} \\ Núcleo de Pesquisa em Plantas Medicinais e Condimentares, Instituto Federal de Educação, \\ Ciência e Tecnologia do Rio Grande do Norte-IFRN, Campus Currais \\ Novos, Professor Pesquisador-Chefe do NUPLAC, Biólogo, Especialista e Mestre em \\ Desenvolvimento e Meio Ambiente pela Universidade do Estado do Rio Grande do Norte. \\ E-mail. angelo.gurgel@ifrn.edu.br
}

Fábio Gonçalves Macêdo de Medeiros

Núcleo de Pesquisa em Plantas Medicinais e Condimentares, Instituto Federal de Educação, Ciência e Tecnologia do Rio Grande do Norte-IFRN, Campus Currais

Novos, Aluno do Curso Técnico Integrado em Informática e Bolsista de Iniciação

Científica na Área de Microbiologia de Alimentos.

E-mail. fabio.macedo@live.com

Jéssica Anarellis Barbosa dos Santos

Núcleo de Pesquisa em Plantas Medicinais e Condimentares, Instituto Federal de Educação, Ciência e Tecnologia do Rio Grande do Norte-IFRN, Campus Currais

Novos, Aluna do Curso Técnico Integrado em Alimentos, com Ampla Experiência Prática na Área de Microbiologia e Biotecnologia de Alimentos.

E-mail.janarellis@gmail.com

\section{RESUMO}

A resistência bacteriana a antibióticos é um sério problema de saúde pública. Bactérias patogênicas como a Listeria monocytogenes, Staphylococcus aureus e Staphylococcus epidermis apresentam cepas resistentes, representando grave risco à saúde humana. A prospecção de fitoquímicos antimicrobianos é apontada como uma possível solução para o problema. Os óleos essenciais de espécies vegetais da caatinga têm sido testados em relação ao seu potencial antimicrobiano. Dentre as espécies medicinais da caatinga produtoras de óleo essencial encontra-se a Lippia gracilis Schauer, cujo fitocomplexo contém carvacrol, timol, $\rho$ cimeno, em concentrações variáveis. Apesar de sua composição e atividades biológicas apontarem para aplicações práticas no controle de patógenos humanos, a ação do óleo essencial desta espécie sobre bactérias patogênicas ainda não foi devidamente avaliada. Quadruplicatas de Placas de Petri contendo Agar Mueller-Hinton foram semeadas em superfície com culturas padronizadas dos microrganismos mencionados. Foram perfurados poços de $10 \mathrm{~mm}$ de diâmetro nos quais se inoculou $100 \mu \mathrm{L}$ de cada diluição do óleo essencial de L.gracilis. As placas foram incubadas a $35 \pm 2{ }^{\circ} \mathrm{C} / 24 \mathrm{~h}$. Os halos de inibição foram mensurados com paquímetro. Todos os microrganismo-alvo foram fortemente inibidos. Sendo a maior inibição alcançada com O.E não diluído sobre o S. epidermis. S. aureus mostrou-se 
como o mais sensível sendo inibido em concentração de O.E de $9 \mu \mathrm{L} / \mathrm{mL}$; L. monocytogenes também foi fortemente inibido pelo óleo essencial de Lippia gracilis.

PALAVRAS-CHAVE: resistência, antimicrobiano, carvacrol, Staphylococcus, Listeria

\title{
ANTIMICROBIAL ACTIVITY OF Lippia gracilis SCHAUER ESSENTIAL OIL ON IMPORTANTS PATHOGENS IN THE FOOD INDUSTRY
}

\begin{abstract}
The microbial resistence to antibiotics is a serious problem of public heath. Pathogenic bacteria such as Listeria monocytogenes, Staphylococccus aureus and Staphylococcus epidermis present resistant strains, representing a serious danger to human health The prospection of antimicrobial phytochemical is sighted how a possible solution to the problem. The vegetal species essential oil of the caatinga have bin tested about its antimicrobial potential. Among the medicinal species essential oil producer at the caatinga is fended the Lippia gracilis Schauer, which phytocomplex contains carvacrol, thymol e $\rho$-cymeno, in variable concentrations. Despite its composition and biological activity sight to practice applications in the control of human pathogens, the action of the essential oil of this specie on pathogenic bacteria still wasn " $t$ justly evaluated. Quadruplicates of petri plates containing Mueller-Hington agar were spreader in surface with padronized cultures of the mentioned microorganisms. Well with $10 \mathrm{~mm}$ of diameter were perforated un which were inoculated 100 $\mu \mathrm{L}$ from each diluition of Lippia gracilis essential oil. The plates were incubated at $35 \pm 2^{\circ} \mathrm{C} / 24 \mathrm{~h}$. The halos of inhibitions were mensurated with paquímeter. All the microorganism-target were strongly inhibited. The larger inhibition reached with E.O. nondiluted on the S. epidermis. S. aureus were the most sensible, being inhibited in concentrations of E.O. of $9 \mu \mathrm{L} / \mathrm{mL}$. L. monocytogenes also was strongly inhibited by the Lippia gracilis essential oil.
\end{abstract}

WORD-KEYS: resistence, antimicrobial, carvacrol, Staphylococcus, Listeria 


\section{ATIVIDADE ANTIBACTERIANA DO ÓLEO ESSENCIAL DE LIPPIA GRACILIS SCHAUER SOBRE PATÓGENOS DE IMPORTÂNCIA NA INDÚSTRIA DE ALIMENTOS}

\section{INTRODUÇÃO}

Nos últimos séculos, a resistência microbiana frente aos antibacterianos vêm tornado-se um sério risco a saúde coletiva, dificultando e impondo diversas barreiras ao controle de microrganismos patogênicos de interesse médico-sanitário. Tal fenômeno deriva do uso indiscriminado de antibióticos, ou é resultado de recombinações entre genes ou mutação entre espécies. A resistência, portanto, é sempre resultante de uma alteração no genótipo do organismo.

Bactérias patogênicas como Listeria monocytogenes, Staphylococcus aureus e Staphylococcus epidermis despontam-se como contaminantes comuns na indústria de alimentos e instalações hospitalares. Tais microrganismos apresentam cepas resistentes aos antibióticos usuais, tornando a sua ocorrência em alimentos e superfícies de trabalho uma ameaça potencial à saúde coletiva.

Diante do aumento de casos de infecções de natureza bacteriana resistente e da dificuldade do controle da proliferação bacteriana em instalações da indústria alimentícia, o uso de bioativos oriundos da flora nativa tem sido apontada como uma possível solução para o problema. Desse modo, têm sido realizados esforços visando à prospecção, o isolamento e a caracterização de princípios ativos para utilização direta em fitofármacos.

A megadiversidade brasileira, resultado das adaptações dos organismos às amplas variações nas condições edafoclimáticas do país, representa uma reserva potencial de novos fitoquímicos bioativos. Dentre as partes vegetais mais pesquisadas na busca de atividades biológicas, destacam-se os óleos essenciais, compostos oleosos aromáticos, de composição complexa. Os óleos essenciais extraídos a partir de várias espécies medicinais nativas têm demonstrado eficiente atividade antimicrobiana frente à patógenos de interesse médicosanitário.

Com base nesta afirmação, o óleo essencial de espécies da flora medicinal da caatinga apresentam-se como uma fonte promissora de novos antimicrobianos. Das quais se destacam as espécies pertencentes ao Gênero Lippia, Família Verbenaceae, mais significativamente destacamos a Lippia gracilis Schauer, popularmente conhecida como alecrim da chapada, alecrim de serrote, alecrim pimenta, cidreira da serra ou alecrim de tabuleiro. O óleo essencial obtido a partir desta espécie contém concentrações variáveis de fitoquímicos, que lhe confere atividade antibacteriana eficaz.

Apesar de sua composição e atividades biológicas apontarem para aplicações práticas no controle de patógenos humanos na indústria de alimentos e hospitais, a ação do óleo essencial de Lippia gracilis sobre bactérias clinicamente importantes ainda não foi devidamente avaliada.

\section{FUNDAMENTAÇÃO TEÓRICA}

Nas últimas décadas, a resistência bacteriana frente aos antimicrobianos constituiu um sério problema para a saúde pública, impondo barreiras ao controle de diversas espécies de 
microrganismos de interesse médico-sanitário (BACCARO et al., 2002; MANTILLA et al.,2008; NAWAZ, 2002). A resistência microbiana pode ocorrer naturalmente, fruto direto de mutação, ou pode ser adquirida através de fenômenos de recombinação gênica entre bactérias. A resistência é vinculada à transferência de plasmídeos, ou através de pequenos segmentos de DNA denominados transposons, capazes de transpor o DNA, de uma região à outra. (TORTORA et al, 2005). A resistência, portanto, é sempre resultante de uma alteração no genótipo do organismo (MANTILLA et al., 2008).

Patógenos como Listeria monocytogenes, Staphylococcus aureus e Staphylococcus epidermis destacam-se entre os contaminantes comuns na indústria alimentícia, sendo relevantes do ponto de vista médico-sanitário. Tais espécies apresentam cepas resistentes aos antibióticos comumente utilizados, tornando a sua presença em alimentos e superfícies de trabalho uma ameaça potencial à saúde humana (BACCARO et al., 2002; GAYOSO et al., 2007; RAPINI et al., 2007; MANTILLA et al., 2008; RIBEIRO et al., 2006).

Diante do aumento de casos de infecções de natureza bacteriana resistentes às drogas antimicrobianas e da dificuldade do controle de cepas resistentes em instalações da indústria alimentícia, o uso de bioativos oriundos da flora nativa tem sido apontada como uma possível solução para o problema. Desse modo, tem sido realizados esforços visando a prospecção, o isolamento e a caracterização de princípios ativos para utilização direta em fitofármacos, ou para o uso como templates na síntese de novas drogas (FERREIRA, 1998).

A megadiversidade brasileira, produto das adaptações dos organismos às diversas variações nas condições climáticas do país, representa uma reserva potencial de novos fitoquímicos bioativos. No fitocomplexo de nossas plantas medicinais estão presentes centenas de substâncias, fruto das interações entre o vegetal e os fatores bióticos e abióticos externos, tais como: a disponibilidade hídrica, condições climáticas, a presença de microbiota associada ao solo, água ou ao próprio vegetal, e as interações inter e intra-específicas com outras espécies presentes no ambiente (CAPASSO et al., 2000; FUNARI \& FERRO, 2005; VARNA et al., 2008).

Dentre as frações vegetais usualmente pesquisadas em busca de atividades biológicas, destacam-se os óleos essenciais. Também denominados "óleos voláteis", são compostos oleosos aromáticos, de composição complexa contendo dentre outros componentes, hidrocarbonetos terpênicos, ésteres, ácidos orgânicos, aldeídos, cetonas e fenóis, em concentrações variáveis em dependência de diversos fatores, sendo que a composição majoritária é representada por um composto farmacologicamente ativo (BURT, 2007). Os óleos essenciais extraídos a partir de várias espécies medicinais nativas têm demonstrado eficiente atividade antimicrobiana frente à patógenos de interesse médico-sanitário (VIOLANTE, 2008; RAMOS et al., 2009; DUARTE et al., 2007; LEMOS et al., 2006).

$\mathrm{Na}$ medicina tradicional nordestina, muitas espécies são utilizadas para o tratamento de infecções (MATOS, 1987). Dentre as espécies, destacamos a Lippia gracilis Schauer, popularmente conhecida como alecrim da chapada, alecrim de serrote, alecrim pimenta, cidreira da serra ou alecrim de tabuleiro. Arbusto ramificado de até 2 metros de altura, com caule quebradiço, folhas simples e pequenas (cerca de $1 \mathrm{~cm}$ de comprimento), aromáticas e picantes, dotadas de nervação impressa claramente visível. Seu fruto é do tipo aquênio, muito pequeno, com sementes de germinação rara. O óleo essencial obtido a partir desta espécie contém concentrações variáveis de compostos orgânicos com atividade antibacteriana eficaz, destacando-se o carvacrol, o timol, e o $\rho$-cimeno (ALBUQUERQUE et al., 2006; BURT, 
2007; CAVALCANTI, 2006; CENTRO NORDESTINO DE INFORMAÇÕES SOBRE PLANTAS, 2009; DUKE, 2009; NETO, 2007; NEVES et al., 2008).

Mesmo sua composição e atividades biológicas apontarem para aplicações práticas no controle de patógenos humanos na indústria e hospitais, a ação do óleo essencial de Lippia gracilis sobre bactérias clinicamente importantes ainda não foi completamente avaliada. Desse modo, o trabalho objetivou caracterizar a atividade antibacteriana sobre os patógenos Listeria monocytogenes, Staphylococcus aureus (ATCC 25923) e Staphylococcus epidermis, importantes contaminantes da indústria de alimentos e microrganismos relevantes à saúde pública

\section{METODOLOGIA}

\section{EXTRAÇÃO DO ÓLEO ESSENCIAL DE LIPPIA GRACILIS.}

A amostra de óleo essencial estada foi extraída a partir de folhas frescas de L. gracilis Schauer, provenientes do cultivar pertencente ao Laboratório de Cultura de Tecidos da Universidade do Estado do Rio Grande do Norte (UERN). A extração foi realizada por arraste por vapor, utilizando o sistema Clevenger, no Laboratório de Química de Produtos Naturais da mesma Universidade. O óleo essencial obtido foi estocado em frasco hermético, protegido da luz. O frasco com a amostra foi acondicionado em gelo e transportado para o Laboratório de Alimentos do IFRN Campus Currais Novos, onde permaneceu sob refrigeração a $-10^{\circ} \mathrm{C}$ até o momento de sua utilização.

\section{MICRORGANISMOS-ALVO}

A atividade antibacteriana do óleo essencial foi testada sobre os microrganismos Listeria monocytogenes Staphylococcu aureus (ATCC 25923) e Staphylococcus epidermis. As respectivas culturas puras foram obtidas a partir da bacterioteca do IFRN Campus Currais Novos.

\section{PADRONIZAÇÃO DO INOCULO}

Os inóculos foram padronizados utilizando-se o padrão 0,5 da escala McFarland. Os microrganismos foram inoculados em tubos de ensaio contendo caldo BHI e incubados a $37^{\circ} \mathrm{C}$ em condições aeróbias por 2 a 6 horas, após o que foram comparadas ao padrão McFarland 0,5. Quando necessário, a turbidez da cultura foi ajustada com uso de solução salina estéril, imediatamente antes da semeadura nas placas (ALVES et al., 2008; NCCLS, 2003).

\section{PREPARO DAS DILUIÇÕES DO ÓLEO ESSENCIAL}

Objetivando permitir a obtenção das diluições necessárias ao experimento, bem como uma melhor difusão das mesmas no ágar foi utilizado tween 80 a 1\% (CAVALCANTI, 2006), em solução salina estéril. Foram testadas as concentrações: $100 \mu \mathrm{L} / \mathrm{mL} ; 8 \mu \mathrm{L} / \mathrm{mL} ; 40 \mu \mathrm{L} / \mathrm{mL}$; $20 \mu \mathrm{L} / \mathrm{mL} ; 10 \mu \mathrm{L} / \mathrm{mL} ; 5 \mu \mathrm{L} / \mathrm{mL}$. Após a adição dos componentes, os tubos contendo as diluições foram submetidos a agitador mecânico tipo vórtex por dois minutos, repetindo-se a operação imediatamente antes do uso. 


\section{INOCULAÇÃO DAS PLACAS DE TESTE}

Foram utilizadas placas de petri de $100 \mathrm{~mm}$ de diâmetro, contendo cerca de $60 \mathrm{~mL}$ de ágar Mueller-Hinton, previamente identificadas. As placas foram semeadas pelo método spread plate, com utilização de swab estéril. Para cada espécie de microrganismo foram inoculadas placas em quadruplicata. As placas foram mantidas entreabertas na Cabine de Segurança Biológica pelo tempo máximo de 5 minutos, permitindo a absorção/evaporação do excesso de umidade (NCCLS, 2003).

\section{TESTE DE DIFUSÃO EM ÁGAR E LEITURA DOS RESULTADOS}

Em cada uma das placas semeadas, foram perfurados 7 poços, sendo um deles central e os demais periféricos. A distância mínima entre os poços foi de aproximadamente $20 \mathrm{~mm}$. Para cada poço respectivamente foi transferido $100 \mu 1$ de cada diluição de óleo essencial (VALGAS, 2007). O controle positivo foi inoculado no poço central, ao qual foi adicionado $100 \mu \mathrm{l}$ de Cloranfenicol $(4 \mathrm{mg} / \mathrm{mL})$. As placas foram incubadas a $37{ }^{\circ} \mathrm{C} / 18 \mathrm{~h}$ em condições aeróbias, após o que se verificou a ocorrência de crescimento uniforme dos microrganismos e a presença de halo de inibição. Os diâmetros dos halos foram mensurados com uso de paquímetro, incluindo-se nestes o valor correspondente aos poços. (NCCLS, 2003).

\section{RESULTADOS E DISCUSSÕES}

Na tabela 1, estão contidos os diâmetros dos halos de inibição do óleo essencial de Lippia gracilis não-diluído; na figura 1 , o diâmetro dos halos de inibição na concentração de $100 \mu \mathrm{L} / \mathrm{mL}$ e na figura 2 , a concentração inibitória mínima do O.E. De acordo com os resultados expressos na tabela 1, podemos afirmar que o óleo essencial de Lippia gracilis inibe o crescimento potencial dos microrganismos testados e que o diâmetro dos halos obtidos, quando comparados com os do controle positivo de Cloranfenicol $(4 \mathrm{mg} / \mathrm{mL})$ indica inibição maior que a do antibiótico testado em contraprova.

Tabela 1: Diâmetro dos maiores halos de inibição observados, obtidos a partir do O.E de Lippia gracilis não-diluído comparado com o antibiótico cloranfenicol.

\begin{tabular}{c|c|c}
\hline Microrganismo & $\begin{array}{c}\text { Óleo Essencial de } \\
\text { Lippia gracilis } \\
(\mathrm{mm})\end{array}$ & $\begin{array}{c}\text { Cloranfenicol } \\
4 \mathrm{mg} / \mathrm{mL} \\
(\mathrm{mm})\end{array}$ \\
\hline Listeria monocytogenes & $\mathbf{3 4}$ & $\mathbf{3 2}$ \\
\hline Staphylococcus aureus & $\mathbf{3 6}$ & $\mathbf{3 3}$ \\
\hline Staphylococcus epidermis & $\mathbf{4 0}$ & $\mathbf{2 1}$ \\
\hline
\end{tabular}

A capacidade inibitória acima observada pode ser explicada pela presença de compostos com ação antimicrobiana comprovada. Estudos realizados em amostras do óleo essencial de $L$. gracilis Schauer obtidas em Pernambuco/PE, estabeleceu as concentrações entre 36,4 a 45\% para carvacrol; $18,1-26,2 \%$ de $\rho$-cimeno e $37,4 \%$ de timol. Nestas concentrações, os compostos acima conferem ao óleo essencial de L. gracilis atividade antibacteriana eficaz (ALBUQUERQUE et al. , 2006; BURT, 2007; CAVALCANTI, 2006; NETO, 2007; NEVES et al., 2008). 


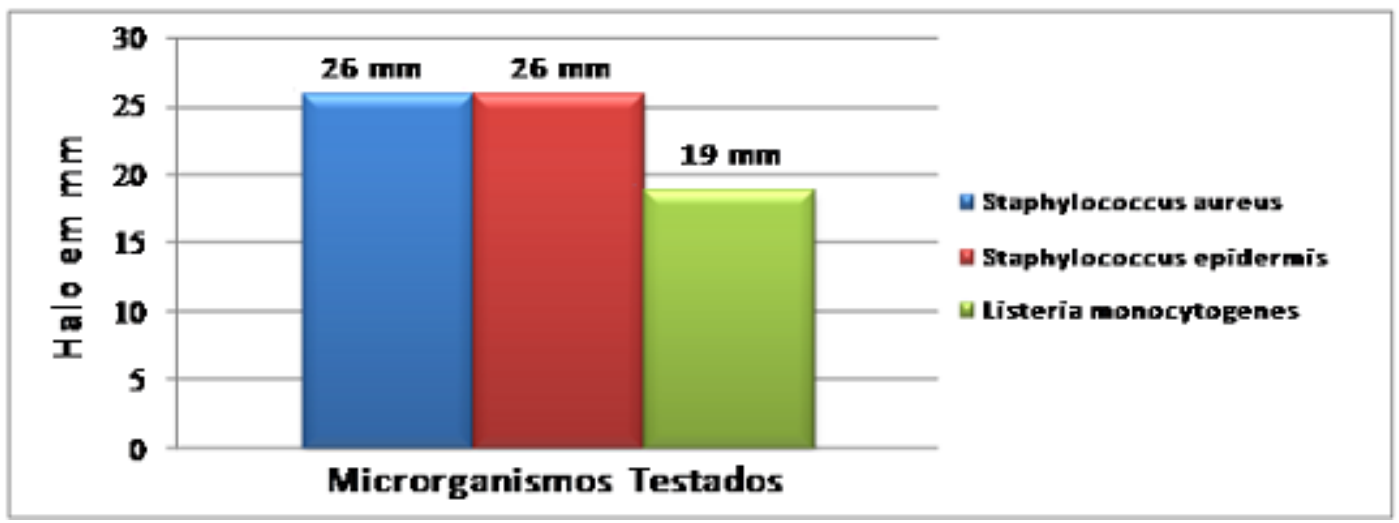

Figura 1 - Diâmetro dos halos de inibição em $(\mathrm{mm})$ na concentração de $100 \mu \mathrm{L} / \mathrm{mL}$ de Óleo Essencial de Lippia gracilis.

De acordo com a figura 1, o diâmetro dos halos de inibição observados nos microrganismos $S$. aureus e S. epidermis na concentração de $100 \mu \mathrm{L} / \mathrm{mL}$ foram os mesmos, o que era esperado, já que, estes microrganismos são da mesma espécie. Para o microrganismo L. monocytogenes o halo $(\mathrm{mm})$ apresentado foi consideravelmente menor, contudo, não é desprezível.

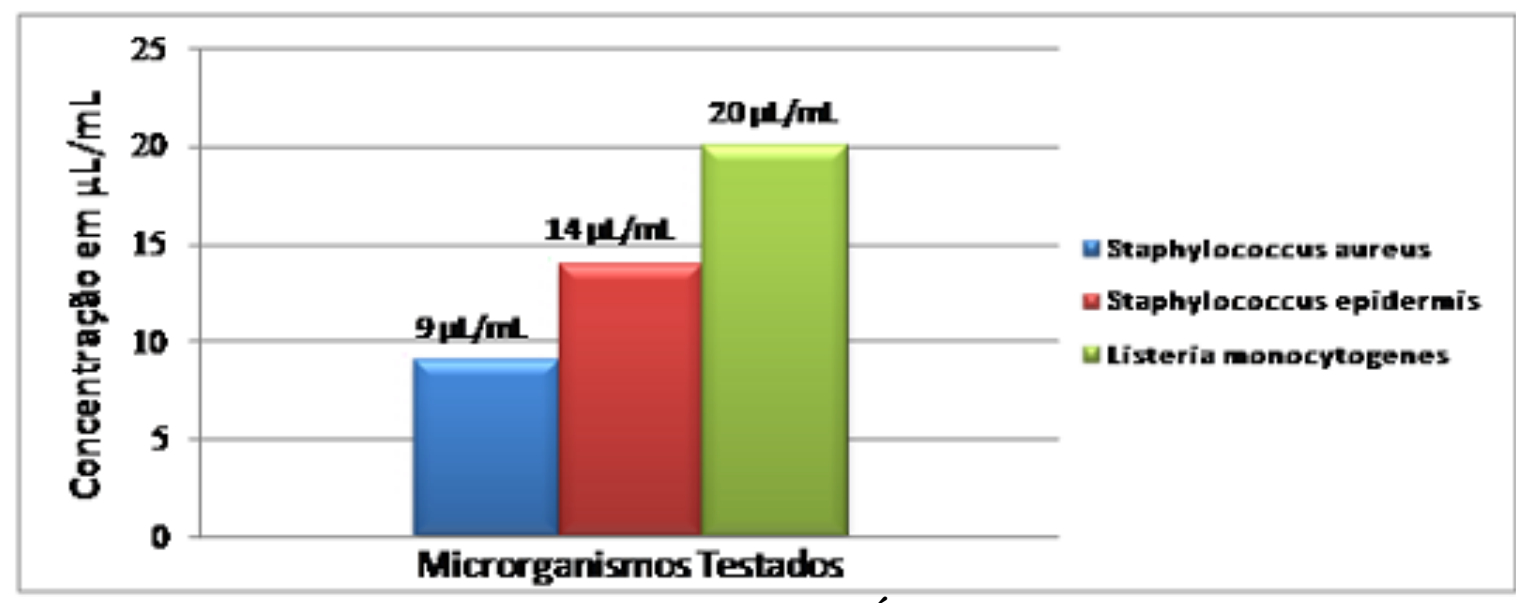

Figura 2 - Concentração Inibitória Mínima do Óleo Essencial de Lippia gracilis em que os microrganismos testados foram inibidos.

Diante dos resultados expressos na figura 2, podemos dizer que o microrganismo S. aureus mostrou-se como o mais sensível ao O.E, pois foi inibido em concentração mínima de $9 \mu \mathrm{L} / \mathrm{mL}$, expressando dessa forma a ampla ação exercida sobre este patógeno. S. epidermis foi inibido também em uma concentração mínima de O.E de Lippia gracilis bem inferior. $L$. monocytogenes dentre os patógenos testados, quando comparado a CIM, apresentou-se como o menos sensível ao O.E sendo inibido em concentração mínima de $20 \mu \mathrm{L} / \mathrm{mL}$.

Em estudos realizados por Burt (2007), comprovou-se a existência de uma interação entre o carvacrol e o timol compostos bioativos do Óleo Essencial de Lippia gracilis, resultando em uma ação sinergística entre os compostos potencializando a ação de ambos frente ao controle das células bacterianas.

\section{CONSIDERAÇÕES FINAIS}

O óleo essencial de Lippia gracilis apresentou atividade inibitória satisfatória sobre todos os microrganismos testados, demonstrando o amplo espectro de ação mesmo quando submetido 
a concentrações mínimas do O.E. A inibição em concentrações mínimas foi mais considerável sobre S. aureus $(9 \mu \mathrm{L} / \mathrm{mL})$, quando comparado a inibição frente ao antibiótico cloranfenicol $4 \mathrm{mg} / \mathrm{mL}$ a inibição foi mais considerável para S. epidermis $(40 \mathrm{~mm})$. Novos bioensaios estão sendo efetuados para se determinar a ação bacteriostática e/ou bactericida do óleo essencial de Lippia gracilis Schauer produzido a partir do cultivar da Universidade do Estado do Rio Grande do Norte. UERN.

\section{REFERÊNCIAS}

1. AlBUQUERQUE, C. CAVALCANTI DE; CAMARA, T. R.; MARIANO, R DE LIMA R.; WILLADINO, L.; MARCELINO JÚNIOR, C.; ULISSES, C.. Antimicrobial action of the essential oil of Lippia gracilis Schauer. Brazilian archives of biology and technology: an international journal. V.49, n. 4, p. 527-535, Jul. 2006

2. AlveS, E. G.; VINHOLIS, A. H. C.; CASEMIRO L. A.; JACOMETTI, N. A.; FURTADO, C.; MARTINS, C. H. G.. Estudo comparativo de técnicas de screening para avaliação da atividade antibacteriana de extratos brutos de espécies vegetais $e$ de substâncias puras. Quim. Nova. V 31, n5, p1224-1229, 2008.

3. BACCARO, M. R.; MORENO, A. M.; CORRÊA, A.; FERREIRA, A. J. P.; CALDERARO, F. F.. Resistência antimicrobiana de amostras de Escherichia coli isoladas de fezes de leitões com diarréia. Arq. Inst. Biol., São Paulo, v 69, n 2, p 15 18, abr-jun, 2002.

4. BURT, SARAH ANN. Antibacterial activity of essential oils: potential aplication in food. Netherlands, Utrecht: Utrecht University, 2007. ISBN/EAN: 978-90-393-4661-7.

5. CAPASSO, R,; IZZO, A.A.; PINTO, L; BIFULCO, T,; VITOBELLO, C.; MASCOLO, N. Phytotherapy and quality of herbal medicines. Fitoterapia, n. 71, p. 58, 2000.

6. CAVALCANTI, V. O.. Atividade micobacteriana do oleo essencial de Lippia gracillis Schauer. Dissertação. Recife, UFPE, 2006.

7. CENTRO NORDESTINO DE INFORMAÇÕES SOBRE PLANTAS. Checklist de plantas do nordeste In: Associação Plantas do Nordeste. Disponível em: <http://www.cnip.org.br/bdpn/ficha.php?cookieBD=cnip7\&taxon=5935>. Acesso em 16 nov. 2009.

8. DUARTE, M. C.; LEME, E. E.; DELARMELINA C.; SOARES, A. A.; FIGUEIRA, G. M.; SARTORATTO, A. Activity of essential oils from brazilian medicinal plants on Escherichia coli. Journal of ethnopharmacology, 111(2):197-20, mai 2007. 
9. DUKE, JAMES A. Phytochemical and Ethnobotanical Databases. Activities of a specific chemical query. 2009. Disponível em: <http://www.ars-grin.gov/duke/chemactivities.html>. Acesso em 16 nov. 2009.

10. FERREIRA, SÉRGIO H. (Sup.). Medicamentos a partir de plantas medicinais no Brasil. Academia Brasileira de Ciências, 1998.

11. FUNARI, C.S., FERRO, V. O. Uso ético da biodiversidade brasileira: uma necessidade e uma oportunidade. Revista Brasileira de Frmacognosia. Journal of Pharmacology, vol. 15, supl. 2, p. 178-182, abr.-jun., 2005.

12. GAYOSO, M. DE FÁtimA A.; OLIVEIRA, A. D. D.; D „AZEVEDO, P. A.; YU, M. C. Z.; HOFLING-LIMA, A. L.. FRANCISCO, W. Suscetibilidade antimicrobiana in vitro dos Staphylococcus coagulase negativa oculares. Arq. Bras. De Oftalmo., 70, 2007.

13. LEMOS, T. L. G; MATOS, F. J. A.; ALENCAR, J. W.; CRAVEIRO, A. A.; CLARK, A. M.; MCCHESNEY, J. D.. Antimicrobial activity of essential oils of brazilian medicinal plants. Phytotherapy reasearch. V.4 issue 2, p 82-84, 1990.

14. MANTILlA, S. P. S.; FRANCO, R. M.; OLIVEIRA, L. A. T. DE OLIVEIRA; SANTOS, E. B.; GOUVÊA, R.. Resistência antimicrobiana de bactérias do gênero Listeria spp. Isoladas de carne moída bovina. Braz. J. Vet. Res. Anim. Sci. V 45, n 2, p 116-121, 2008.

15. MATOS, F.J.A.; MACHADO, M.I.L.; CRAVEIRO, A.A.; ALENCAR, J.W.; SILVA, M.G.V. Medicinal plants of northeast Brazil containing thymol and carvacrol Lippia sidoides Cham. and Lippia gracilis H.B.K. (Verbenaceae). J. Essent. Oil Res. 11, 666-668,1999.

16. NAWAZ, M.S. Human health impact and regulatory issues involving antimicrobial resistance in the food animal production environment. Disponível em: <http://www.fda.gov>. Acesso em 22 out 2002.

17. NCCLS. Performance standards for antimicrobial disk susceptibility tests: approved standard. 8 ed. NCCLS Document M2-A8. Pensylvania, USA, 2003.

18. NETO, RENATO MOTA. Lippia Aff gracilis, Lippia gracilis e L-Glutamina e suas ações antibac-teriana antioxidante $\mathrm{e}$ imunoduladora em modelos de ratos diabéticos. Dissertação. Fortaleza: UFC, 2007. 
19. NEVES LLZENAYDE A.; DE OLIVEIRA JOSE C. S.; DA CAMARA CLAUDIO A. G.; SCHWARTZ MANFRED O. E. Chemical Composition of the Leaf Oils of Lippia gracilis Schauer from two Localities of Pernambuco. The Journal of essential oil research, 2008, v. 20, n.2, p. 157-160.

20. RAMOS, S. C. S.; OLIVEIRA, J. C. S. DE; CÂMARA, C. A. G. DA; CASTELAR, I.; CARVALHO, A. F. F. U.; LIMA-FILHO, J. V.. Antibacterial and cytotoxic properties of some plant crude extracts used in Northeastern folk medicine. Brazilian Journal of pharmacognosy, 19(2A): 376-381, Abr./Jun. 2009.

21. RAPINI, L. S.; TEIXEIRA, J. P.; MARTINS, N. E. CERQUEIRA, M. M. O. P.; SOUZA, M. R.; PENNA, C. F. A. M.. Perfil de resistência antimicrobiana de cepas de Staphylococcus sp. Isoladas de queijo tipo coalho. Arq. Bras. Méd. Vet. Zootec.. v 56, n1, p 130-133, 2004.

22. RIBEIRO, A. R.; KELLERMANN, A.; SANTOS, L. R.; FITTÉL, A.P.; NASCIMENTO, V. P.. Resistência antimicrobiana em Salmonella enterica subsp enterica sorovar hadar isoladas de carcaças de frango. Arq. Inst. Biol. V 73, n 3, p 357-360. jun-set, 2006.

23. VAlGAS, C.; SOUZA, S. M DE. SMÂNIA, E. F. A.; SMÂNIA JUNIOR, A.. Screening methods to determine antibacterial activity of natural products. Brazilian Journal of microbiology. 38: 369-380. 2007

24. 24.VARNA, A.; ABBOT, L.; WERNER, D.; HAMPP, R.. Plant surface microbiology. New York: Springer-Verlag, 2008. ISBN 978-3-540-74050-6.

25. VIOLANTE, I. M. P. Avaliação do potencial antimicrobiano e citotóxico de espécies vegetais do cerrado da região centro-oeste. Dissertação. UFMS, 2008.

26. TORTORA, G. J.; FUNKE, B. R.; CASE, C. L.. Microbiologia. 8ed. Porto Alegre, Artmed, 2005. 